\title{
Erratum to: Lens artifacts in human fetal eyes - the challenge of interpreting the histomorphology of human fetal lenses
}

\author{
Martina C. Herwig • Annette M. Müller • \\ Ute Klarmann-Schulz • Frank G. Holz • Karin U. Loeffler
}

Published online: 2 April 2014

(C) Springer-Verlag Berlin Heidelberg 2014

\section{Erratum to: Graefes Arch Clin Exp Ophthalmol \\ DOI 10.1007/s00417-013-2485-2}

Reason: The pictures and subtitles have been interchanged in the original publication.

Corrected version: The figure legend of Fig. 5 belongs to Fig. 4, the figure legend of Fig. 6 belongs to Fig. 5, and the figure legend of Fig. 6 belongs to the flow chart. The assignment of the figures (e.g. Fig. 3) in the text and the subtitle of each figure are correct - however, the wrong figure is depicted.

The online version of the original article can be found at doi:10.1007/ s00417-013-2485-2.

M. C. Herwig $(\bowtie) \cdot$ F. G. Holz $\cdot$ K. U. Loeffler

Department of Ophthalmology, University of Bonn, Ernst-Abbe-Str.

2, 53127 Bonn, Germany

e-mail: martina.herwig@ukb.uni-bonn.de

M. C. Herwig $\cdot$ K. U. Loeffler

Division of Ophthalmic Pathology, University of Bonn,

Ernst-Abbe-Str. 2, 53127 Bonn, Germany

\section{A. M. Müller}

Department of Pediatric Pathology, University of Bonn,

Sigmund-Freud-Str. 25, 53127 Bonn, Germany

\section{U. Klarmann-Schulz}

Institute for Medical Biometry, Informatics and Epidemiology,

University Hospital Bonn, Sigmund-Freud-Str. 25, 53127 Bonn,

Germany 